\title{
MISIRoot: A Robotic Minimum Invasion in Situ Imaging System for Plant Root Phenotyping
}

\section{Zhihang Song}

Purdue University

Wei Qiu

Nanjing Agricultural University

Jian Jin ( $\sim$ jinjian@purdue.edu )

Purdue University https://orcid.org/0000-0003-4188-1951

\section{Research}

Keywords: Plant root phenotyping, root imaging, 3D point cloud, minimally invasive root measurement, low-cost root phenotyping, robotic arm application

Posted Date: September 9th, 2020

DOl: https://doi.org/10.21203/rs.3.rs-25184/v2

License: @ (i) This work is licensed under a Creative Commons Attribution 4.0 International License. Read Full License 
The authors have withdrawn this preprint from Research Square 